Check for updates

Cite this: Mater. Adv., 2021,

2, 1600

Received 7th July 2020,

Accepted 28th January 2021

DOI: $10.1039 / \mathrm{d} 0 \mathrm{ma} 00484 \mathrm{~g}$

rsc.li/materials-advances

\section{Additive manufacturing of multielectrode arrays for biotechnological applications $\uparrow$}

\author{
Amelia V. Edwards, $\ddagger^{a}$ Christopher Hann, $\ddagger^{a}$ Henry Ivill, $\ddagger^{a}$ Hanna Leeson, $\ddagger^{a}$ \\ Larysa Tymczyszyn, $\neq^{a}$ Damian M. Cummings, (D) b Mark D. Ashton, (iD c \\ Garry R. Harper, (DD ' ${ }^{c}$ Diane T. Spencer, ${ }^{d}$ Wan Li Low, ID e Kiron Rajeev, \\ Pierre Martin-Hirsch, ${ }^{9}$ Frances A. Edwards, (D) *b John G. Hardy, (D) *ch \\ Allan E. W. Rennie (D) *a and David Cheneler (ID *ah
}

Multielectrode arrays (MEAs) are electrical devices that transduce (record/deliver) cellular voltage signals. Commercially available MEAs are expensive and here we provide proof of concept for the application of an additive manufacturing approach to prepare inexpensive MEAs and demonstrate their ability to interact with brain tissue ex vivo.

Electrodes (optionally in arrays [e.g. microelectrode/multielectrode arrays]) can record/stimulate electrical signals to/from biological samples. ${ }^{1-8}$ Excited muscle cells and neurons enable the flow of ion currents through their cell membranes via voltage-gated ion channels. Recording electrodes convert environmental voltages carried by ions into electronic currents, and stimulating electrodes convert electronic currents into ionic currents in the environment (e.g. medium/tissue). The voltage differences inside/outside cells trigger the voltage-gated ion channels in the cell membranes of muscle cells and neurons to depolarize, and this depolarization triggers a twitch in muscle cells or an action potential in neurons. ${ }^{9}$

MEAs to record/stimulate electrical signals have been designed for in vitro, ${ }^{9-15}$ ex vivo ${ }^{16-20}$ and in vivo applications, ${ }^{3,4,21-24}$ where

\footnotetext{
${ }^{a}$ Department of Engineering, Lancaster University, Lancaster, LA1 4YW, UK. E-mail: a.rennie@lancaster.ac.uk, d.cheneler@lancaster.ac.uk

${ }^{b}$ Department of Neuroscience, Physiology and Pharmacology, University College London, London, WC1E 6BT, UK. E-mail: f.a.edwards@ucl.ac.uk

${ }^{c}$ Department of Chemistry, Lancaster University, Lancaster, LA1 4YB, UK. E-mail: j.g.hardy@lancaster.ac.uk

${ }^{d}$ Rosalind Franklin Building, Faculty of Science and Engineering, University of Wolverhampton, Stafford Street, Wolverhampton, West Midlands, WV1 1NA, UK

${ }^{e}$ School of Pharmacy, Faculty of Science and Engineering, University of Wolverhampton, Wolverhampton, West Midlands, WV1 1LY, UK

${ }^{f}$ NeuDrive Ltd, National Printable Electronics Centre, NETPark, County Durham, TS21 3FG, UK

${ }^{g}$ Lancashire Teaching Hospitals NHS Trust, Royal Preston Hospital, Sharoe Green Lane, Preston, PR2 9HT, UK

${ }^{h}$ Materials Science Institute, Lancaster University, Lancaster, LA1 4YB, UK

$\dagger$ Electronic supplementary information (ESI) available. See DOI: 10.1039/ d0ma00484g

\$ Authors contributed equally.
}

the signal's magnitude and shape are governed by the specific properties of the experimental paradigm: circuit design, electrode dimensions/impedance/material, quality of cell-electrode contact, properties of the medium/tissue (capacitance, conductivity and homogeneity), and signal processing. There are commercially available MEAs (typically metal-/alloy-based) ${ }^{15,25-28}$ that are manufactured by standard methods, such as lithography ${ }^{29}$ or electrochemical micromachining, ${ }^{30}$ however, they are expensive.

MEAs can be produced from a variety of conductive materials (e.g. carbon nanotubes [CNTs], ${ }^{31,32}$ gold, indium-tin oxide, iridium oxide, nickel, platinum, silicon, steel), ${ }^{3,4,23,24,33}$ deposited on a nonconductive support substrate (e.g. glass, polydimethylsiloxane [PDMS]), with appropriately positioned insulation materials (e.g. parylene, silicon nitride, SU-8 epoxy resin and polyimide). The charge transfer properties of the electrodes depends on their surface area and the thickness of the electrode-electrolyte double layer, and the electrode surfaces may be modified (e.g. ablated/ coated) to produce electrodes with low impedances to ensure high signal-to-noise ratios. ${ }^{34,35}$

Additive manufacturing (AM) techniques are capable of producing components for electronic applications. ${ }^{36-39}$ The aim of this study was to use AM methods to produce inexpensive MEAs (arrays of at least six by six electrodes) with non-exposed tracks for the purpose of exciting nerve tissue and validate their efficacy in electrical signal transduction in an ex vivo model system (mouse brain slices). This AM method enables other researchers to produce bespoke MEAs designed to suit the specific requirements of the paradigms/samples to be studied.

A variety of AM methods can be employed to produce MEAs, ${ }^{36-40}$ and here MEAs were produced via the injection of conductive materials into substrates fabricated using AM. ${ }^{41}$ Preliminary prototyping was carried out with polylactide (PLA) filament using a Z-Morph 2SX Multi-Tool 3D Printer, an Ultimaker 2+ and a Stratasys J750, of which the Stratasys J750 produced the highest fidelity parts with minimal/no porosity (Fig. S1 and Tables S1, S2, ESI $\dagger$ ). Consequently, a Stratasys J750 was used to print MEA substrates with hollow channels that were subsequently filled with 
A

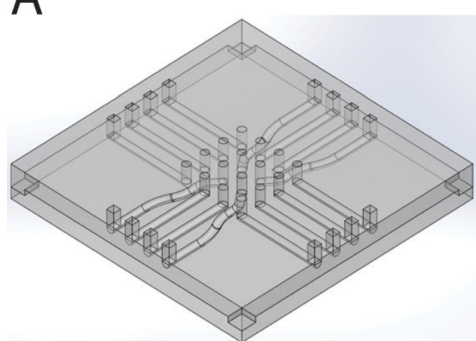

C Stage 1) Design of MEA substrates.

Stage 2) Print MEA substrates.

Stage 3) Fill channels in MEA substrates with conductive material. Stage 4) Annealing/Finishing.

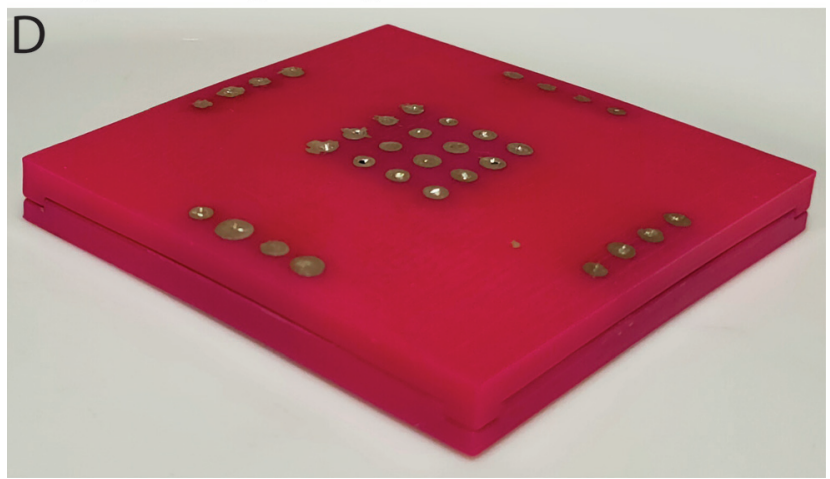

Fig. 1 (A) CAD model of MEA including cutouts on the bottom half and extrusions on the top half in the corresponding positions to clip the halves together, ensure alignment of the electrodes and ensure the MEA could be handled easily in the laboratory. (B) Top view of CAD model of MEA. (C) Summary of the MEA production process. (D) Photograph of a silver contact MEA (sides $50 \mathrm{~mm}$, height $3 \mathrm{~mm}$ ).

conductive materials to create electrode channels. $\mathrm{Wu}$ and colleagues reported that filling channels with widths less than $400 \mu \mathrm{m}$ in analogous structures was often unsuccessful, ${ }^{36}$ consequently the dimensions of the channels in the computer aided design (CAD) model were greater than $400 \mu \mathrm{m}$ (Fig. 1A and B). ${ }^{42}$ Attempts to produce the non-conductive MEA supports with tracks to be filled with conductive materials led to the conclusion that splitting the MEA in half along the horizontal axis and filling the two halves separately should allow for ease of manufacture without compromising functionality in accordance with the prototype specification in Table S3 (ESI $\dagger$ ). Aligning the top and bottom accurately with planar halves was challenging due to the lack of a guiding mechanism, resulting in the tendency of the halves to slide out of position when pressure was applied. Consequently, recesses on the bottom half and extrusions on the top half in the corresponding positions were employed to mate the halves together, ensure alignment of the electrodes and ensure the MEAs could be handled easily in the laboratory (Fig. 1A and B), using the process outlined in Fig. 1C, and described in a step-bystep fashion for the silver contact MEAs in Table S4 (ESI $\dagger$ ) and the CNTs/PDMS contact MEAs in Table S5 (ESI $\dagger$ ).

It is possible to prepare MEAs with silver-based electrodes using a commercially available paste to fill the channels electrode tracks. The paste was too viscous to be injected easily, necessitating the addition of a dispersing agent (either acetone or $\alpha$-terpineol, the latter of which was listed as the dispersant in the commercially available paste). It was observed that formulations with $\alpha$-terpineol were smoother and more consistent facilitating easier transfer from mixing container into syringes for subsequent injection, and its lower volatility than acetone enabled storage of batches for a few days. The conductive channels in the MEA structures produced after evaporation of all of the dispersing agents were composed of silver microparticles (20 wt\% $<5 \mu \mathrm{m}$ in diameter) and nanoparticles (80 wt\% ca. $200 \mathrm{~nm}$ in diameter). The surface of the entire MEAs were sanded and the individual electrodes were painted with silver paint, yielding silver MEAs (Fig. S2, ESI $\dagger$ ). It is possible to prepare MEAs with electrodes composed of composites of CNTs and PDMS by injection of a degassed paste composed of CNTs suspended in uncured silicone elastomer into the MEA channels (Fig. S3, ESI $\dagger$ ), followed by curing, yielding CNTs/PDMS MEAs. In the long term we expect the manual channel filling process to be automated to increase the production rate, thereby facilitating rapid optimisation of the prototype MEAs for specific applications and potentially enabling their production (batch/mass) by other methods.

PLA is an FDA-approved polymer that is generally recognized as safe (GRAS), and we conducted in silico toxicity screening of the other components utilised in the production of the prototype MEAs (Table S6, ESI $\dagger$ ) using commercially available software (Derek Nexus $^{43}$ (Derek Nexus: v. 6.0.1, Nexus: 2.2.2) and Sarah Nexus $^{44}$ (Sarah Nexus: v. 3.0.0, Sarah Model: 2.0) to assess potential hazards (Derek identifies structural alerts for several endpoints and Sarah is a statistical-based model focused on mutagenicity only) during production and use, that we have previously applied to materials for bioelectronic applications. ${ }^{45,46}$ For the silver contact MEAs Derek Nexus suggested some potential for $\alpha$-terpineol to induce skin sensitization, ${ }^{47-49}$ and to be nephrotoxic (due to the presence of the terpenoid and tertiary alcohol in the structure, respectively), Sarah Nexus suggested that acetone may be mutagenic ( $6 \%$ confidence), and risks from these solvents can be diminished by production in a controlled environment (e.g. fume hood) and vacuum drying. The in silico studies did not identify silver as a sensitiser or mutagen (the in silico models are usually developed for and based on data for organic compounds), however, other studies have identified allergenic/irritant responses and toxicity (genotoxic, hepatic, renal, neurological, and hematological effects) dependent on the form of silver (ions, metallic, or nanoparticle) and dose of silver exposure. ${ }^{50}$ For the CNTs/PDMS contact MEAs Derek Nexus suggested some potential for the CNTs to induce skin sensitization due to the presence of conjugated dienes in their structures ${ }^{51}$ (and other studies have reported a variety of toxic effects resulting from CNTs); ${ }^{52-60}$ PDMS may be hepatotoxic and nephrotoxic due to the organosilicon and ether functionalities present in the PDMS, ${ }^{61}$ respectively (and other studies have reported the toxicity of siloxanes in various scenarios). ${ }^{62-64}$ In the case of the materials described in this work, it is possible to contemplate their use as MEAs that would be removed after short term exposure in vivo, or use for in vitro and ex vivo studies, followed by safe disposal. 
A 4-point probe was used to assess the sheet resistance of the materials $\left(\Omega \mathrm{sq}^{-1}\right)$. The sheet resistance of the uncured silver ink was $0.51 \pm 0.04 \Omega \mathrm{sq}^{-1}$, which increased after curing to $3.56 \pm 0.59 \Omega \mathrm{sq}^{-1}$; the silver paint used within/on the MEAs had an average resistance of $26.73 \pm 6.62 \Omega \mathrm{sq}^{-1}$ if uncured, and $0.70 \pm 0.04 \Omega \mathrm{sq}^{-1}$ after curing; and the average resistance of the silver painted and cured MEA channels was found to be $1.81 \pm 0.46 \Omega \mathrm{sq}^{-1}$. By comparison, the average sheet resistance of the MEAs filled with CNTs/PDMS was found to be $152 \pm 29 \mathrm{k} \Omega \mathrm{sq}^{-1}$. The through channel conductivity of the silver electrodes is $3.7 \pm 0.2 \mathrm{~S} \mathrm{~cm}^{-1}$ and for the CNTs/PDMS electrodes it is $0.5 \pm 0.3 \mathrm{mS} \mathrm{cm}^{-1}$.

Simple and effective sterilization methodologies for bespoke MEAs would help enable their storage and potential reuse. Sterilisation by exposure to ethylene oxide (EO) and gammairradiation sterilization are effective methodologies, but were ruled out due to their inaccessibility in many laboratories and slow processing for EO. ${ }^{65}$ Autoclaving with high pressure saturated steam at $121{ }^{\circ} \mathrm{C}$ for $20 \mathrm{~min}$ was ruled out as the steam might hydrolyse the backbone of the PLA used to print the MEA templates with channels; dry heat autoclaving (at 160$170{ }^{\circ} \mathrm{C}$ for $20 \mathrm{~min}$ ) was ruled out because the temperature is similar to the melting point of PLA (although thermogravimetric analysis demonstrated the onset of decomposition of the polymer was significantly higher, as per Fig. S4 and S5, ESI $\dagger$ ). The MEAs produced were stable to brief exposure to aqueous ethanol or aqueous isopropanol followed by UV irradiation, which represents a pragmatic solution for laboratories undertaking electrophysiology studies in vitro and ex vivo in academic and nonacademic environments.

Measurements of the force required to break the MEAs were undertaken using an experimental paradigm replicating an individual holding the MEA with their index and middle finger beneath it while applying pressure to the top surface with their thumb, based on studies finding forces of up to $179 \mathrm{~N}$ exerted using index fingers, and up to $290 \mathrm{~N}$ exerted using thumbs. ${ }^{66}$ We observed the MEAs were robust towards the likely external forces acting upon them using a three-point flexural load testing model (Fig. S6, ESI $\dagger$ ) and shear testing (Fig. S7, ESI $\dagger$ ). The stability of the electrical and chemical properties of the prototype silver MEAs was assessed by immersion of the MEAs in PBS for a period of 2 weeks which is significantly longer than their use is envisioned. The average impedance of the MEA tracks were very consistent over the period of the experiment, confirming the stability of the electrical properties of the electrode arrays (Fig. 2). Likewise, ICP-OES confirmed that no leaching of the $\mathrm{Ag}$ was observed over the period of the experiment (Fig. 2).

To validate the efficacy of the prototype MEAs for being able to apply a stimulus in biological applications, the ability of the MEAs to interact with a slice of mouse brain ex vivo resulting in controlled stimulation of a neuronal pathway was assessed. An acute brain slice was placed onto the MEA, which was then used to deliver an electrical stimulus to CA3 efferent axons. To verify that action potentials had successfully been activated resulting in synaptic transmission, a postsynaptic response
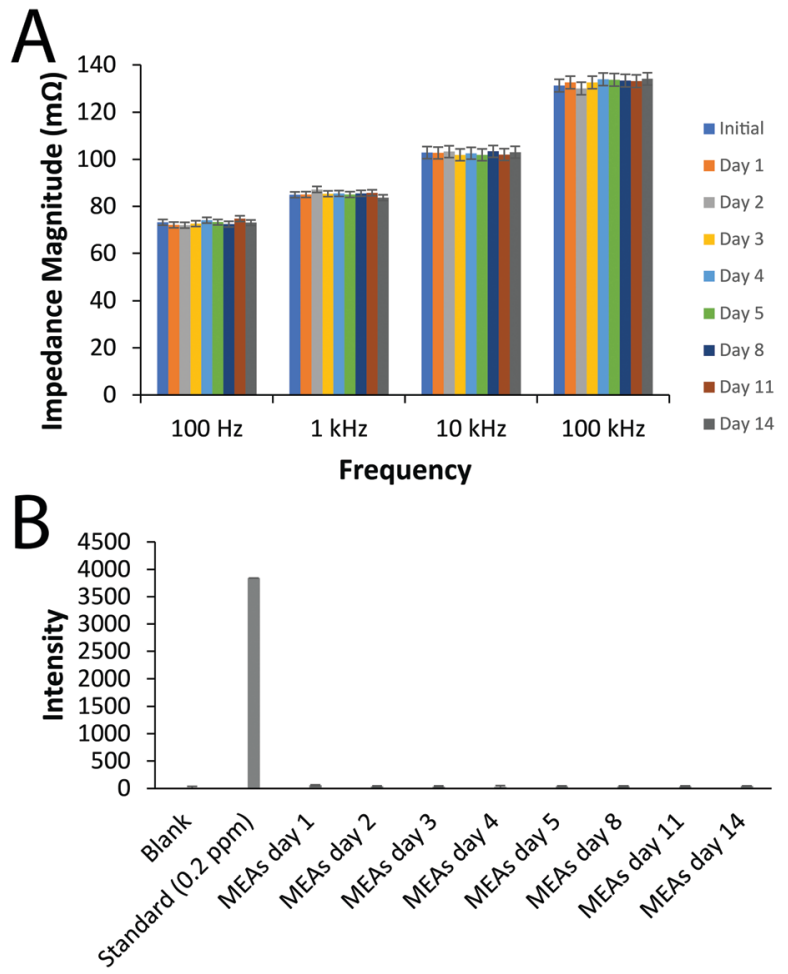

Fig. 2 Stability of the electrical and chemical properties of the prototype silver MEAs in vitro for 2 weeks. (A) Impedance measurements. (B) ICP-OES measurements.

(fEPSP) was then recorded, using a conventional glass electrode placed amongst the proximal apical dendrites of CA1 pyramidal neurones. ${ }^{67,68}$ Constant voltage stimulation via the silver contact MEAs evoked fEPSPs, with a good signal-to-noise ratio, although with a wide stimulus artefact (Fig. 3).

Typical of CA3-CA1 synapses, fEPSPs displayed paired-pulse facilitation, whereby two identical stimuli in quick succession gives rise to a larger response on the second stimulation. The mean \pm standard error of the paired-pulse ratio recorded over a 10 min period was $1.25 \pm 0.04$, indicative of the low probability of neurotransmitter (glutamate) release expected in healthy brain tissue. ${ }^{69}$ Over the 10 min period, the slope of the first fEPSP was stable (calculated using WIN-WCP, Fig. S8, ESI $\dagger$ ). A tetanic conditioning stimulus train was then applied. Immediately following tetanus, the slope of the first fEPSPs increased in size and remained $>170 \%$ of the average baseline response for the first 2 min post-tetanus. This initial increase is known as post-tetanic potentiation and is mediated by an increase in probability of glutamate release caused by unbuffered calcium in the presynaptic terminal. The increased probability of release was reflected by a decreased paired-pulse ratio ( $0.65 \pm 0.2)$, as paired-pulse ratio is inversely proportional to probability of release. By $3 \mathrm{~min}$, the fEPSPs were $120-150 \%$ of baseline and remained so for the rest of the experiment. This is short-term potentiation and the very earliest stages of long-term potentiation, the best cellular mechanism to explain learning and memory. ${ }^{69}$ Between 11-20 mins, the paired-pulse ratio had recovered to $1.18 \pm 0.08$, which is not significantly different 


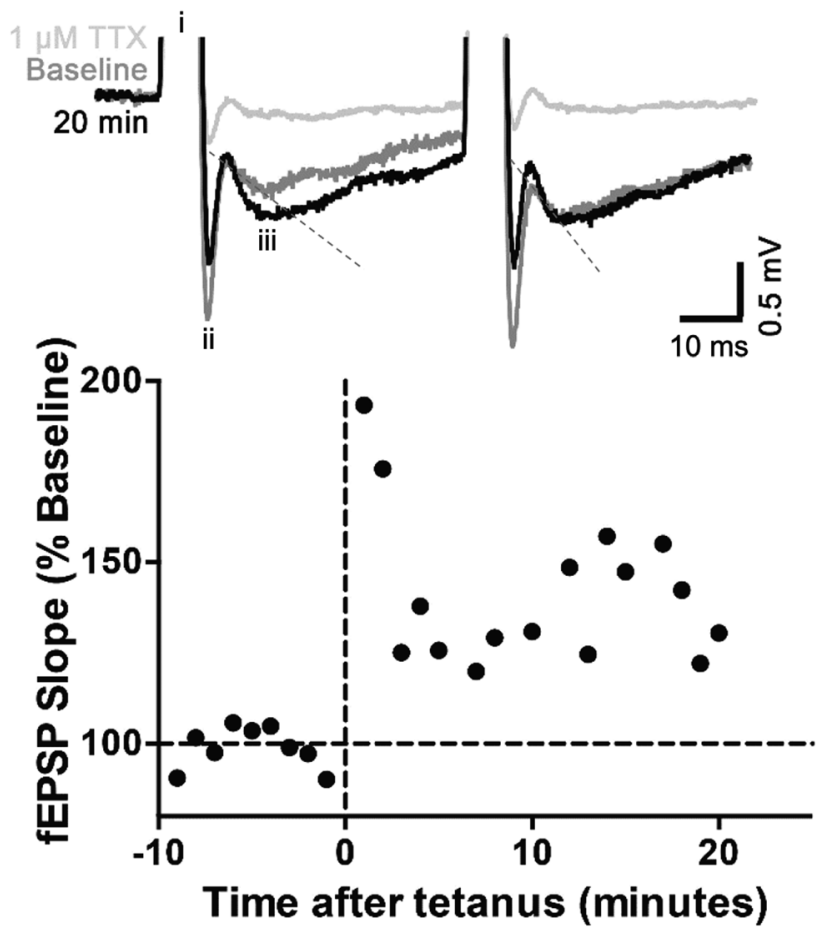

Fig. 3 Validation of the efficacy of the prototype silver MEAs for biological applications, as demonstrated by the ability of the silver MEAs to interact with a slice of mouse brain ex vivo. Top: Example fEPSPs of baseline (dark grey), 20 minutes after tetanus (black) and subsequently in the presence of $1 \mu \mathrm{M}$ TTX (pale grey). The broad stimulus artefact (i) has been attenuated for graphical presentation. The first negative deflection (ii) is an interaction of the stimulus artefact with the 'axon volley', the presynaptic action potential evoked by the stimulus. The second negative deflection is the fEPSP (iii). The slope is measured (blue dashed line indicated on the dark grey baseline fEPSP) as the slope of a linear fit from 10 to 50\% maximum amplitude. Note that paired-pulse facilitation, typical of CA3-CA1 synapses, is evident (second response steeper than the first). Bottom: fEPSP slope plotted as percent of baseline. Tetanic stimulation (20 stimuli at $100 \mathrm{~Hz}$, repeated 3 times at $1.5 \mathrm{~s}$ intervals) induced synaptic plasticity typical of CA3-CA1 synapses, including post-tetanic potentiation $(0-2$ minutes after tetanus), short-term potentiation ( $<10 \mathrm{~min}$ after tetanus) and the very early stages of long-term potentiation ( $20 \mathrm{~min}$ after tetanus).

from baseline. Thus, little if any change in release probability remained and the increase in fEPSP was mediated by postsynaptic alterations, such as glutamate (AMPA) receptor phosphorylation or extra AMPA receptors being inserted into the synapse. ${ }^{69}$ Finally, to confirm the physiological basis of the responses, the voltage-gated sodium channel blocker tetrodotoxin (TTX, $1 \mu \mathrm{M}$ ) was applied, which blocks action potentials, thus preventing glutamate release. In the presence of TTX, the fEPSP was abolished.

We further demonstrate in this proof of concept trial that the silver-coated electrodes made contact more effectively than the CNTs/PDMS contact MEAs. Despite the silicone electrodes effectively producing electrical output as demonstrated by a clear stimulus artefact in response to single or high-frequency pulses (Fig. S9, ESI $\dagger$ ), constant voltage stimulation failed to result in a physiological response. The occurrence of a clear stimulus artefact but no response (Fig. S9, ESI $\dagger$ ) suggests poor contact between the carbon nanotubes and the mouse brain slice so the electrical output did not result in the stimulation of the axon pathway. Stimuli ranging from $0-100 \mathrm{~V}$ and 2-100 $\mu \mathrm{s}$ were tested. However, as demonstrated by the silver coated electrodes, when optimised the MEA can be used in biological situations requiring high-frequency stimulation, such as experiments similar to that using the silver contact MEAs to induce long-term potentiation (Fig. S9, ESI $\dagger$ ) or any other situation where repetitive stimuli applied to nerve tissue would be desirable.

\section{Conclusions}

Herein we report an AM approach to the preparation of bespoke MEAs for biotechnological applications. The MEAs with either silver or CNTs/PDMS electrodes were characterized, as was their ability to interact with a slice of mouse brain (ex vivo) on the application of an electrical stimulus, yielding MEAs displaying good signal-to-noise ratios. The cost of the silver contact MEAs was calculated to be $c a$. $£ 36$ ( $c a$. \$47 US Dollars in January 2021) per MEA (factoring in: substrate costs calculated using PolyJet Studio, supplied with the Stratasys J750, including the cyan material used with the support material to help with adhesion and strength; from user experience, one syringe could be used for two MEAs, with five needles being needed per MEA due to clogging which was less problematic for $\alpha$-terpineol formulations), which we believe could be reduced if the MEAs were to be manufactured in a more controlled environment (e.g. using an automated channel filling process to increase the production rate). This is cheaper than the price of MEAs currently marketed that are manufactured by traditional methods, mainly due to the reduction in the number of processes involved in the AM process. Such prototype MEAs should be able to be reused a few times to offer the user an opportunity to hone their experiment and/or change the size/position of the electrodes; however, while the CNTs and PDMS are stable over prolonged periods, it is foreseeable that the PLA and silver will degrade over time, consequently, we do not propose these prototypes for indefinite use. Moreover we demonstrate the importance of testing the particular type of electrode for the proposed use. The AM process described here is specifically designed for stimulation of nerve activity in biological tissues but it could easily be adapted for recording signals or other industrially relevant biotechnological applications (e.g. 3D printed vessels with embedded electrodes to measure the concentration of dissolved $\mathrm{O}_{2}$ and $\mathrm{pH}$ in high throughput bioreactors, or biodegradable MEAs). ${ }^{70-74}$

\section{Statement of contributions}

Conceptualization, F. A. E., J. G. H., A. E. W. R., D. C.; methodology, A. E., C. H., H. I., H. L., L. T., D. M. C., M. D. A., G. R. H., D. T. S., W. L. L., F. A. E., J. G. H., A. E. W. R., D. C.; formal analysis, all authors; investigation, (materials preparation: A. E., C. H., H. I., H. L., L. T., G. R. H.; materials characterization. A. E., C. H., H. I., 
H. L., L. T., M. D. A., G. R. H., D. T. S.; electrophysiology: D. M. C.), data curation, W. L. L., F. A. E., J. G. H., A. E. W. R., D. C.; writing-original draft preparation, J. G. H.; writing-review and editing, all authors; supervision, W. L. L., F. A. E., J. G. H., A. E. W. R., D. C.; project administration, J. G. H; funding acquisition, F. A. E., J. G. H., A. E. W. R., D. C., P. M. H.

\section{Conflicts of interest}

There are no conflicts to declare. The funders had no role in the design of the study; in the collection, analyses, or interpretation of data; in the writing of the manuscript, or in the decision to publish the results. The views expressed are those of the authors and not necessarily those of the National Health Service (NHS), the National Institute for Health Research (NIHR) or the Department of Health.

\section{Acknowledgements}

J. G. H., A. E. W. R., D. C., F. A. E. and K. R. thank the UK Biotechnology and Biological Sciences Research Council (BBSRC) Network in Industrial Biotechnology and Bioenergy (NIBB) scheme for a Business Interaction Voucher (BB/L013762/1). F. A. E. thanks the UK Medical Research Council (MRC) for financial support (MR/J011851/1). J. G. H. thanks the UK Engineering and Physical Sciences Research Council (EPSRC) for financial support (EP/R511560/1 and EP/R003823/1), the BBSRC for a proof-ofconcept grant (BB/L0137971/1), the UK Royal Society for financial support (RG160449), and the MRC for supporting interactions with P. M. H. (MC_PC_17192). At Lancaster University we thank Tom Abram, Dimitrios Afouxenidis, Sara J. Baldock, Peter Jones and Richard Wilbraham for informative discussions, and Geoffrey Holroyd for access to a biological safety cabinet. At Lhasa Limited, we thank staff for informative discussions. At Plymouth Marine Laboratory, we thank Mike J. Allen for informative discussions.

\section{Notes and references}

1 R. A. Normann, Nat. Clin. Pract. Neurol., 2007, 3, 444-452.

2 A. Ajetunmobi, A. Prina-Mello, Y. Volkov, A. Corvin and D. Tropea, Prog. Neurobiol., 2014, 123, 18-36.

3 P. Fattahi, G. Yang, G. Kim and M. R. Abidian, Adv. Mater., 2014, 26, 1846-1885.

4 Z. Fekete, Sens. Actuators, B, 2015, 215, 300-315.

5 L. Paninski and J. P. Cunningham, Curr. Opin. Neurobiol., 2018, 50, 232-241.

6 B. J. Black, R. Atmaramani, S. Plagens, Z. T. Campbell, G. Dussor, T. J. Price and J. J. Pancrazio, Biosens. Bioelectron., 2019, 126, 679-689.

7 D. Cheneler, J. Bowen and G. Kaklamani, J. Electr. Bioimpedance, 2014, 5, 55-73.

8 D. Cheneler, E. Buselli, D. Camboni, C. Anthony, L. Grover, M. J. Adams and C. M. Oddo, Sensors, 2014, 14, 23781-23802.

9 X. J. Duan, T. M. Fu, J. Liu and C. M. Lieber, Nano Today, 2013, 8, 351-373.
10 S. Martinoia, L. Bonzano, A. Chiappalone, A. Tedesco, A. Marcoli and G. Maura, Biosens. Bioelectron., 2005, 20, 2071-2078.

11 T. Hannes, M. Halbach, R. Nazzal, L. Frenzel, T. Saric, M. Khalil, J. Hescheler, K. Brockmeier and F. Pillekamp, J. Electrocardiol., 2008, 41, 562-566.

12 R. Morales, M. Riss, L. Wang, R. Gavin, J. A. Del Rio, R. Alcubilla and E. Claverol-Tinture, Lab Chip, 2008, 8, 1896-1905.

13 S. C. Schock, K. S. Jolin-Dahel, P. C. Schock, S. Theiss, G. W. Arbuthnott, M. Garcia-Munoz and W. A. Staines, J. Neurosci. Methods, 2012, 205, 324-333.

14 S. L. Edwards, V. Zlochiver, D. B. Conrad, R. Vaidyanathan, A. M. Valiquette and R. Joshi-Mukherjee, Stem Cell Rep., 2018, 11, 522-536.

15 M. E. Spira, S. H. Huang, N. Shmoel and H. Erez, Adv. Neurobiol., 2019, 22, 125-153.

16 A. J. Blake, F. C. Rodgers, A. Bassuener, J. A. Hippensteel, T. M. Pearce, T. R. Pearce, E. D. Zarnowska, R. A. Pearce and J. C. Williams, J. Neurosci. Methods, 2010, 189, 5-13.

17 G. Gholmieh, W. Soussou, M. Han, A. Ahuja, M. C. Hsiao, D. Song, A. R. Tanguay and T. W. Berger, J. Neurosci. Methods, 2006, 152, 116-129.

18 D. E. Gunning, J. M. Beggs, W. Dabrowski, P. Hottowy, C. J. Kenney, A. Sher, A. M. Litke and K. Mathieson, J. Neural Eng., 2013, 10, 016007.

19 S. Ito, F. C. Yeh, E. Hiolski, P. Rydygier, D. E. Gunning, P. Hottowy, N. Timme, A. M. Litke and J. M. Beggs, PLoS One, 2014, 9, e105324.

20 G. Panuccio, I. Colombi and M. Chiappalone, J. Vis. Exp., 2018, 57548.

21 R. M. Rothschild, Front. Neuroeng., 2010, 3, 112.

22 C. A. Brunello, V. Jokinen, P. Sakha, H. Terazono, F. Nomura, T. Kaneko, S. E. Lauri, S. Franssila, C. Rivera, K. Yasuda and H. J. Huttunen, J. Nanobiotechnol., 2013, 11, 11.

23 K. Scholten and E. Meng, Lab Chip, 2015, 15, 4256-4272.

24 N. P. Pampaloni, M. Giugliano, D. Scaini, L. Ballerini and R. Rauti, Front. Neurosci., 2019, 12, 00953.

25 J. Dowling, Eye, 2009, 23, 1999-2005.

26 N. G. Hatsopoulos and J. P. Donoghue, Annu. Rev. Neurosci., 2009, 32, 249-266.

27 A. F. M. Johnstone, G. W. Gross, D. G. Weiss, O. H. U. Schroeder, A. Gramowski and T. J. Shafer, Neurotoxicology, 2010, 31, 331-350.

28 N. L. Deep, B. Choudhury and J. T. Roland, J. Neurol Surg. B Skull Base, 2019, 80, 203-208.

29 J. Wigstrom, J. Dunevall, N. Najafinobar, J. Lovric, J. Wang, A. G. Ewing and A. S. Cans, Anal. Chem., 2016, 88, 2080-2087.

30 M. H. Wang, Z. Y. Bao, X. F. Wang and X. F. Xu, Precis. Eng., 2016, 46, 184-192.

31 L. Bareket-Keren and Y. Hanein, Front. Neural Circuits, 2013, 6, 00122.

32 S. K. Rastogi, A. Kalmykov, N. Johnson and T. Cohen-Karni, J. Mater. Chem. B, 2018, 6, 7159-7178. 
33 M. Mahmud and S. Vassanelli, Front. Neurosci., 2016, 10, 00248.

34 J. A. Fairfield, Adv. Funct. Mater., 2018, 28, 1701145.

35 L. Guo, J. Neural Eng., 2020, 17, 013001.

36 S. Y. Wu, C. Yang, W. Y. Hsu and L. W. Lin, Microsyst. Nanoeng., 2015, 1, 15013.

37 T. M. Benedetti, A. Nattestad, A. C. Taylor, S. Beirne and G. G. Wallace, 3D Print. Addit. Manuf., 2018, 5, 215-219.

38 R. S. Jordan and Y. Wang, J. Polym. Sci., Part B: Polym. Phys., 2019, 57, 1592-1605.

39 C. Y. Lee, A. C. Taylor, A. Nattestad, S. Beirne and G. G. Wallace, Joule, 2019, 3, 1835-1849.

40 J. G. Hardy, D. S. Hernandez, D. M. Cummings, F. A. Edwards, J. B. Shear and C. E. Schmidt, J. Mater. Chem. $B, 2015,3,5001-5004$.

41 D. Cheneler, J. G. Hardy and A. E. W. Rennie, presented in part at the 2nd International Conference on Advanced Structural and Functional Materials, Barcelona, 2019.

42 D. Cheneler, Figshare, 2021, DOI: 10.6084/m9.figshare. 13640660.v1.

43 D. S. Macmillan and M. L. Chilton, Regul. Toxicol. Pharmacol., 2019, 101, 35-47.

44 C. Barber, A. Cayley, T. Hanser, A. Harding, C. Heghes, J. D. Vessey, S. Werner, S. K. Weiner, J. Wichard, A. Giddings, S. Glowienke, A. Parenty, A. Brigo, H. P. Spirkl, A. Amberg, R. Kemper and N. Greene, Regul. Toxicol. Pharmacol., 2016, 76, 7-20.

45 M. D. Ashton, I. C. Appen, M. Firlak, N. E. Stanhope, C. E. Schmidt, W. R. Eisenstadt, B. Hur and J. G. Hardy, Polym. Int., 2020, DOI: 10.1002/pi.6089.

46 A. Magaz, M. D. Ashton, R. M. Hathout, X. Li, J. G. Hardy and J. J. Blaker, Pharmaceutics, 2020, 12, 742.

47 M. T. D. Cronin and D. A. Basketter, SAR QSAR Environ. Res., 1994, 2, 159-179.

48 G. F. Gerberick, C. A. Ryan, P. S. Kern, H. Schlatter, R. J. Dearman, I. Kimber, G. Y. Patlewicz and D. A. Basketter, Dermatitis, 2005, 16, 157-202.

49 P. S. Kern, G. F. Gerberick, C. A. Ryan, I. Kimber, A. Aptula and D. A. Basketter, Dermatitis, 2010, 21, 8-32.

50 N. Hadrup, A. K. Sharma and K. Loeschner, Regul. Toxicol. Pharmacol., 2018, 98, 257-267.

51 M. P. Payne and P. T. Walsh, J. Chem. Inf. Comput. Sci., 1994, 34, 154-161.

52 K. Kostarelos, Nat. Biotechnol., 2008, 26, 774-776.

53 L. Lacerda, A. Bianco, M. Prato and K. Kostarelos, Adv. Drug Delivery Rev., 2006, 58, 1460-1470.

54 S. Y. Madani, A. Mandel and A. M. Seifalian, Nano Rev., 2013, 4, 21521.
55 C. J. Serpell, K. Kostarelos and B. G. Davis, ACS Cent. Sci., 2016, 2, 190-200.

56 M. Uo, T. Akasaka, F. Watari, Y. Sato and K. Tohji, Dent. Mater. J., 2011, 30, 245-263.

57 Z. Peng, X. J. Liu, W. Zhang, Z. T. Zeng, Z. F. Liu, C. Zhang, Y. Liu, B. B. Shao, Q. H. Liang, W. W. Tang and X. Z. Yuan, Environ. Int., 2020, 134, 105298.

58 K. Donaldson, R. Aitken, L. Tran, V. Stone, R. Duffin, G. Forrest and A. Alexander, Toxicol. Sci., 2006, 92, 5-22.

59 N. Kobayashi, H. Izumi and Y. Morimoto, J. Occup. Health, 2017, 59, 394-407.

60 K. F. A. Clancy and J. G. Hardy, Curr. Pharm. Des., 2017, 23, 3614-3625.

61 S. G. Haider, O. Stuhl, H. G. Goslar and L. Birkofer, Cell. Mol. Biol., 1983, 29, 299-306.

62 C. Rucker and K. Kummerer, Chem. Rev., 2015, 115, 466-524. 63 F. Pichi, S. Hay and E. B. Abboud, Int. Ophthalmol., 2020, 40, 2413-2422.

64 M. Copeland, M. Choi and I. J. Bleiweiss, Plast. Reconstr. Surg., 1994, 94, 628-633.

65 S. Kim, J. O. Jeong, S. Lee, J. S. Park, H. J. Gwon, S. I. Jeong, J. G. Hardy, Y. M. Lim and J. Y. Lee, Sci. Rep., 2018, 8, 3721.

66 P. S. A. T. Group, Strength Data for design safety - Phase 1, https://webarchive.nationalarchives.gov.uk/20021221085815, http://www.dti.gov.uk:80/homesafetynetwork/pg_rdata.htm, accessed 03/07, 2020.

67 D. M. Cummings, W. F. Liu, E. Portelius, S. Bayram, M. Yasvoina, S. H. Ho, H. Smits, S. S. Ali, R. Steinberg, C. M. Pegasiou, O. T. James, M. Matarin, J. C. Richardson, H. Zetterberg, K. Blennow, J. A. Hardy, D. A. Salih and F. A. Edwards, Brain, 2015, 138, 1992-2004.

68 E. Medawar, T. A. Benway, W. F. Liu, T. A. Hanan, P. Haslehurst, O. T. James, K. Yap, L. Muessig, F. Moroni, M. A. N. Solim, G. Baidildinova, R. Wang, J. C. Richardson, F. Cacucci, D. A. Salih, D. M. Cummings and F. A. Edwards, Ebiomedicine, 2019, 39, 422-435.

69 T. V. P. Bliss and G. L. Collingridge, Mol. Brain, 2013, 6, 5.

70 V. Schroeder, S. Savagatrup, M. He, S. B. Ling and T. M. Swager, Chem. Rev., 2019, 119, 599-663.

71 B. Kim, J. An, D. Fapyane and I. S. Chang, Bioresour. Technol., 2015, 195, 2-13.

72 H. M. Hegab, A. ElMekawy and T. Stakenborg, Biomicrofluidics, 2013, 7, 021502.

73 D. Schapper, M. N. H. Z. Alam, N. Szita, A. E. Lantz and K. V. Gernaey, Anal. Bioanal. Chem., 2009, 395, 679-695.

74 H. A. Galeb, E. L. Wilkinson, A. F. Stowell, H. Y. Lin, S. T. Murphy, P. L. Martin-Hirsch, R. L. Mort, A. M. Taylor and J. G. Hardy, Global Challenges, 2020, 2000102. 